\title{
Methicillin-resistant Staphylococcus aureus among patients in a teaching hospital in Ghana
}

\author{
Akosua Bonsu Karikari ${ }^{1}$, Enoch Frimpong ${ }^{2}$ and Alex Owusu-Ofori ${ }^{2}$
}

1. Department of Clinical Microbiology, University for Development Studies, Tamale, Ghana; 2. Department of Clinical Microbiology, Kwame Nkrumah University of Science and Technology, Kumasi, Ghana.

Corresponding author: Akosua Bonsu Karikari, e-mail: asbuks@yahoo.co.uk

Co-authors: EF: ehfrimps@gmail.com, AOO: owusu_ofori@hotmail.com

Received: 10-05-2017, Accepted: 25-06-2017, Published online: 25-07-2017

doi: 10.14202/IJOH.2017.46-49 How to cite this article: Karikari AB, Frimpong $E$, Owusu-Ofori $A$. Methicillin-resistant Staphylococcus aureus among patients in a teaching hospital in Ghana. Int J One Health 2017;3:46-49.

\begin{abstract}
Aim: This study determined the prevalence of methicillin-resistant Staphylococcus aureus (MRSA) and assessed the resistance profiles of strains.

Materials and Methods: Inpatients and outpatients of all age groups presenting with sepsis as well as skin and soft tissue infections were screened from October 2006 to March 2007. Resistance to methicillin (oxacillin) and other relevant antibiotics was determined by the Kirby-Bauer disk diffusion and minimum inhibitory concentration (MICs) by the E-test (AB, Biodisk, Solna, Sweden).

Results: Methicillin resistance was 34.8\% (87/250), majority (67/87) of which were hospital acquired MRSA. Resistance was $100 \%$ to the $\beta$-lactams, $78.2 \%$ to cotrimoxazole, $75.8 \%$ to tetracycline, $59.8 \%$ to gentamicin, $56.3 \%$ to flucloxacillin, $34.4 \%$ to erythromycin, and $32.2 \%$ to cefuroxime. MIC ranged from 4-256, 0.125-256, 0.064-32, and 1.5-32, respectively, to oxacillin, gentamicin, cotrimoxazole, and ceftriaxone.
\end{abstract}

Conclusion: Prevalence of MRSA is high in Komfo Anokye Teaching Hospital, and routine surveillance should be put in place to monitor the epidemiology of this pathogen.

Keywords: antibiotic resistance, Ghana, Komfo Anokye Teaching Hospital, methicillin-resistant Staphylococcus aureus.

\section{Introduction}

Antibiotic resistance is a global public health threat. Increasingly, high resistance rates are being reported the worldwide among several pathogens to different classes of antibiotics. Methicillin-resistant Staphylococcus aureus (MRSA) is one of the notorious multidrug-resistant organisms causing health care and community-associated infections [1]. Since its discovery in the 1960s, resistance has been identified in this organism, and by the close of that decade, it had been implicated in hospital outbreaks in the United States, Australia, and Europe [2]. In Africa, MRSA strains were first isolated in 1978. From 1986 to 1987 , a hospital outbreak was recorded in South Africa while community acquired-MRSA (CA-MRSA) infections were reported in the 1990s in Zimbabwe [3-5].

MRSA infections are associated with increased morbidity and mortality. Other effects of MRSA may be increased medical cost resulting from prolonged hospital stay as well as limited treatment options often associated with its infections [6,7]. MRSA are

Copyright: Karikari, et al. This article is an open access article distributed under the terms of the Creative Commons Attribution 4.0 International License (http://creativecommons.org/licenses/ by/4.0/), which permits unrestricted use, distribution, and reproduction in any medium, provided you give appropriate credit to the original author(s) and the source, provide a link to the Creative Commons license, and indicate if changes were made. The Creative Commons Public Domain Dedication waiver (http:// creativecommons.org/ publicdomain/zero/1.0/) applies to the data made available in this article, unless otherwise stated. principal agents of bacteremia, pneumonia, endocarditis as well as skin and soft tissue infections $[6,8]$.

Some authors have suggested that the rising incidence of MRSA in many African countries is an obvious threat to the continent [9] but in Ghana few studies have described the prevalence of MRSA [10-12]. Continuous monitoring of multidrug-resistant pathogens such as MRSA is of importance for the creation and implementation of infection control systems. This study reports the prevalence of hospital acquiredMRSA (HA-MRSA) and CA-MRSA among patients attending the Komfo Anokye Teaching Hospital (KATH) in Ghana and its susceptibility profile to some relevant antibiotics.

\section{Materials and Methods}

\section{Ethical approval}

Ethical approval was sought and obtained from the Committee on Human Research, Publication and Ethics, the joint ethics committee of Kwame Nkrumah University of Science and Technology and Komfo Anokye Teaching Hospital in Kumasi, Ghana. Patients consent was sought, and those that agreed to participate in the study were recruited. All specimens were coded, and patients made anonymous by removing identities on samples.

\section{Study population and site}

This study was conducted at the Microbiology Laboratory of the KATH, Kumasi which is the only tertiary health institution in the Ashanti Region and 
the second largest in Ghana. It is a referral hospital of 1200 bed capacity which serves eight regions in Ghana. Patients of all age groups presenting with bloodstream infections as well as skin and soft tissue infections who gave their consent were recruited in the study from October 2006 to March 2007. HA-MRSA was defined as, isolates from all inpatients and outpatients (who have had surgery or been hospitalized within the year), and for CA-MRSA, isolates from all outpatients who have not had surgery or hospitalization within the year of the study. The information for categorization into HA-MRSA and CA-MRSA was obtained through interviews and questionnaire administration.

\section{Sample collection, isolation, and identification}

Inpatients and outpatients diagnosed with sepsis and skin and soft tissue infections whose blood, pus and swab samples were brought into the laboratory for bacteriological analysis were approached for enrollment into the study. Inpatients whose samples tested positive for MRSA were followed up at the various wards and interviewed using a questionnaire. In addition, outpatients who were diagnosed as MRSA positive cases were interviewed. Nurses and medical assistants in the ward assisted in the filling and collection of questionnaire forms of inpatients. Interview and filling of questionnaire forms of outpatients were done when they came for their medical reports from the laboratory. The interview confirmed the information in the medical records. The questionnaire provided the risk factors for grouping the isolates into HA and CA infections.

Blood, pus, wound, nasal, and ear swabs were processed using standard bacteriological methods. Colonies morphologically resembling $S$. aureus were Gram-stained and biochemical test including catalase, slide, and tube coagulase test were carried out to confirm the species.

\section{Antibiotic susceptibility test}

Susceptibility test was performed on Mueller-Hinton agar (Becton Dickinson, UK) using the Kirby-Bauer disc diffusion technique [13]. The following antibiotics at given concentrations were used: Penicillin (1.5 U), ampicillin $(10 \mu \mathrm{g})$, gentamicin $(10 \mu \mathrm{g})$, erythromycin $(5 \mu \mathrm{g})$, tetracycline $(10 \mu \mathrm{g})$, cefuroxime $(30 \mu \mathrm{g})$, flucloxacillin $(5 \mu \mathrm{g})$, and co-trimoxazole (trimethoprim-sulfamethoxazole $(25 \mu \mathrm{g})$, (Mast Diagnostics, UK). Methicillinresistance was tested using $1 \mu \mathrm{g}$ oxacillin disc cartridges (OXOID, UK). Zone diameters were read after incubation at $35^{\circ} \mathrm{C}$ for a full $24 \mathrm{~h}$. Strains with zone sizes of $<10 \mathrm{~mm}$ for oxacillin were regarded as methicillin resistant, or any growth within the zone of inhibition was indicative of methicillin resistance [13]. Oxacillin minimum inhibitory concentrations (MICs) were determined with the E-test strips (AB Biodisk, Solna, Sweden) on 50 MRSA isolates using 0.5 McFarland density inoculum following the manufacturer's instructions. Methicillin susceptibility and methicillin resistance were defined as oxacillin (OXA) E-test MICs of $=2$ and $=4 \mu \mathrm{g} / \mathrm{ml}$, respectively. $S$. aureus ATCC 25923 was the quality control strain.

\section{Statistical analysis}

Statistical analysis was performed using analysis of variance with logistic regression analysis performed to find an association between variables. A $\mathrm{p} \leq 0.05$ was considered statistically significant. Stata 14.0 software was used for statistical analysis.

\section{Results}

Demographic distribution showed $61 \%$ of cases came from females. The mean age of the study group was 11 years, with an age span from $<1$ to 85 -year-old (Table-1). The relationship of sex and age on MRSA prevalence was determined by the univariate and multivariate model. The MRSA status was treated as binary outcome and examined with regard to the individual's sex and age in the logistic models. In the univariate model, females were 1.4 times more likely to have MRSA as males (odds ratio $[\mathrm{OR}]=1.4,95 \%$ confidence interval [CI]: $0.84-2.43)$ and only age group 30-39 was associated with MRSA $(\mathrm{OR}=0.2$, 95\% CI: 0.07-0.89, $\mathrm{p}=0.032$ ).

Of the $250 \mathrm{~S}$. aureus isolated, 87 were resistant to oxacillin giving an MRSA prevalence of $34.8 \%$. Out of the 87 MRSA isolates, HA-MRSA was 67 (26.8\%), and $20(8 \%)$ was CA-MRSA. The difference in isolation rates was not statistically significant, $\mathrm{p}=0.9$.

The 250 samples processed included 211 blood (84.4\%), 19 wound swabs (7.6\%), 8 pus (3.2\%), 6 ear swabs (2.4\%), 2 peritoneal fluid ( $0.4 \%), 2$ nasal swabs $(0.4 \%)$ and 1 each of knee, and pleural aspirates $(0.4 \%)$. Of the 87 MRSA recovered, $86.2 \%(75 / 87)$ was isolated from blood and the remaining $13.8 \%$ (12/75) from miscellaneous samples (pus $-1.1 \%$, nasal swab $-1.1 \%$, ear swab - 2.3\%, and wound swab-9.2\%). The distribution of MRSA infections at the various departments of the hospital was $46.3 \%$ (31) from the mother and baby unit (MBU), 40.3\% (27) for pediatric unit, 3\% (2) each from male surgical and women medical unit, $3 \%$ (2) from outdoor patient and the remaining 1.5\% from postnatal and medical emergency unit. Sepsis and septicemia were the most reported infections in HA-MRSA (58.1\%) followed by pneumonia $(8.9 \%)$ as sepsis was the leading infection in CA-MRSA (40\%) followed by ear infections (10\%).

Table-1: Age distribution of MRSA patients.

\begin{tabular}{lcc}
\hline \multirow{2}{*}{ Age/years } & \multicolumn{2}{c}{ Number of patients (\%) } \\
\cline { 2 - 3 } & HA-MRSA (n=67) & CA-MRSA (n= 20) \\
\hline$<1$ & $44(65.7)$ & $0(0)$ \\
$1-9$ & $17(25.4)$ & $4(20)$ \\
$10-19$ & $0(0)$ & $0(0)$ \\
$20-29$ & $3(4.4)$ & $7(35)$ \\
$30-39$ & $1(1.5)$ & $2(10)$ \\
$40-49$ & $1(1.5)$ & $1(5)$ \\
$50-59$ & $1(1.5)$ & $2(10)$ \\
$>60$ & $0(0)$ & $4(20)$ \\
\hline
\end{tabular}

HA-MRSA $=$ Hospital acquired methicillin resistant Staphylococcus aureus, CA-MRSA=Community acquired-methicillin resistant Staphylococcus aureus 
Susceptibility profiles of HA and CA isolates were $100 \%$ each to penicillin and ampicillin. With the exception of cefuroxime and erythromycin in which resistance was below $50 \%$, the remaining antibiotics showed rates ranging from $50 \%$ to $100 \%$ (Table-2). There was no significant difference in resistance rates of HA and CA isolates ( $\mathrm{p}=0.76$ ).

The E-test showed all 50 MRSA isolates were resistant to oxacillin and 34 and 41 of the isolates were resistant to gentamicin and cotrimoxazole, respectively, with MIC range of 4-256 to oxacillin, 0.125-256 to gentamicin, $0.064-32$ to cotrimoxazole, and 1.5-32 to ceftriaxone (Table-3).

\section{Discussion}

Globally, MRSA has been recovered from different clinical samples at a prevalence range of $23-73 \%$ [14]. In most African countries, the prevalence was $<50 \%$ before the year 2000 but has seen an increased trend in recent times with an exception to South Africa [9]. Few studies that have looked at MRSA prevalence in Ghana showed an ambit of 16.6$47.3 \%[10,11,12,15]$. Our study found MRSA prevalence of $34.8 \%$ which is consistent with reported rates in Ghana and other countries including France, Saudi Arabia, Kenya, and Cameroon [10,16-18] but lower than the $44.2 \%$ reported in Nigeria [19].

Traditionally, MRSA is considered a major nosocomial pathogen in health-care facilities but its involvement in community-associated infections have also been established [5,20]. According to Zetola

Table-2: Susceptibility patterns of HA-MRSA and CA-MRSA isolates.

\begin{tabular}{|c|c|c|c|c|c|c|}
\hline \multirow[t]{2}{*}{ Antibiotic } & \multicolumn{3}{|c|}{$\begin{array}{c}\text { HA-MRSA } \\
(n=67)\end{array}$} & \multicolumn{3}{|c|}{$\begin{array}{c}\text { CA-MRSA } \\
(n=20)\end{array}$} \\
\hline & $\mathbf{s}$ & $\mathbf{I}$ & R (\%) & $\mathbf{s}$ & I & R (\%) \\
\hline & 0 & 0 & $67(100)$ & 0 & 0 & $20(100)$ \\
\hline Ampicillin $(10 \mu \mathrm{g})$ & 0 & 0 & $67(100)$ & 0 & 0 & $20(100)$ \\
\hline Cotrimoxazole $(25 \mu \mathrm{g})$ & 10 & 3 & $54(81)$ & 6 & 0 & $14(70)$ \\
\hline ycline $(10 \mu \mathrm{g})$ & 12 & 5 & $50(75)$ & 3 & 1 & $16(80)$ \\
\hline Gentamicin $(10 \mu \mathrm{g})$ & 17 & 3 & $47(70)$ & 13 & 2 & $5(25)$ \\
\hline Flucloxacillin $(5 \mu \mathrm{g})$ & 12 & 18 & 37 (55) & 3 & 5 & $12(60)$ \\
\hline Cefuroxime $(30 \mu \mathrm{g})$ & 38 & 7 & $22(33)$ & 14 & 0 & $6(30)$ \\
\hline Erythromycin $(5 \mu \mathrm{g})$ & 37 & 9 & $21(31)$ & 11 & 1 & $9(45)$ \\
\hline
\end{tabular}

$\mathrm{S}=$ Sensitive, $\mathrm{I}=$ Intermediate, $\mathrm{R}=$ Resistant,

HA-MRSA = Hospital acquired-methicillin resistant

Staphylococcus aureus, CA-MRSA=Community

acquired-methicillin resistant Staphylococcus aureus

Table-3: MIC of MRSA isolates to four antibiotics.

\begin{tabular}{lccc}
\hline Antibiotic & Range & \multicolumn{2}{c}{$\mathbf{n = 5 0}$ MIC $\boldsymbol{\mu g} / \mathbf{m l}$} \\
\cline { 3 - 4 } & & MIC (50) & MIC (90) \\
\hline Oxacillin & 4 to $\geq 256$ & 48 & 224 \\
Gentamicin & 0.125 to $\geq 256$ & 32 & 256 \\
SXT & 0.064 to $\geq 32$ & 4 & 8 \\
Ceftriaxone & 1.5 to $\geq 32$ & 8 & $\geq 32$ \\
\hline
\end{tabular}

SXT = Trimethoprim sulfamethoxazole $=$ Cotrimoxazole, $\mathrm{MIC}=$ Minimum inhibitory concentration, $\mathrm{MRSA}=$ Methicillin resistant Staphylococcus aureus et al. [20], CA-MRSA did not develop in the community but constitutes a hybrid between MRSA which escaped from the hospital environment.

MRSA bacteremia is mostly associated with higher mortality and may have serious sequelae in infants and children [7]. In our study, MRSA was $74.7 \%$ prevalent among patients aged $<1-9$ years and this could be due to the fact that the Microbiology Department of KATH receives the bulk of blood samples from the MBU and pediatric emergency unit and consequently, MRSA was isolated mainly from blood stream infections (86.2\%). MRSA outbreaks in neonatal intensive care units are well documented [21], and young children tend to have higher colonization rates probably because of their frequent contact with respiratory secretions [22]. In Ghana, an MRSA outbreak was recorded at the children's ward of the Korle-Bu Teaching Hospital [23].

The resistance profile of MRSA isolates revealed generally high resistance to the $\beta$-lactams (penicillin and ampicillin), cotrimoxazole and tetracycline but lower rates $(<50 \%)$ were recorded for cefuroxime and erythromycin. Some studies have also established high resistance $(100 \%)$ to the $\beta$-lactams $[19,24,25], 80 \%$ to cotrimoxazole [26], as well as $78.7 \%$ and $86.8 \%$ to tetracycline $[19,27]$.

In vitro resistance to gentamicin is a good surrogate marker of nosocomial acquisition of MRSA and conversely, CA strains of MRSA are usually gentamicin-susceptible in vitro $[28,29]$. This was affirmed in our study, where $70.1 \%$ of HA-isolates were resistant and $25 \%$ of CA isolates were resistant to gentamicin. Among aminoglycosides, $65.8 \%$ resistance has been reported in Nigeria [19], and 90\% in Eastern Uttar Pradesh [26].

A significant proportion of MRSA isolates was resistant to flucloxacillin which is of concern because it is the drug of choice for treating $S$. aureus infections in this hospital. The relatively low resistance recorded against cefuroxime may be attributed to the cost of the drug as they are rarely prescribed by physicians at KATH compared to the cheaper drugs such as penicillin, ampicillin, erythromycin, gentamicin, and tetracycline. Furthermore, patients and potential drug abusers are discouraged from its purchase due to the high cost. A limitation of this study was our inability to test vancomycin which is the drug of choice for multi-resistant MRSA. At present, in Ghana MRSA is not included in the infections under surveillance because it is not considered a public health problem, but continuous monitoring of its prevalence and susceptibility patterns in our regional and district hospitals are necessary for effective management and control.

\section{Conclusion}

MRSA was prevalent among $34.8 \%$ of patients attending KATH with HA- infections being common. Resistance to penicillin, ampicillin cotrimoxazole, flucloxacillin, and tetracycline was generally high but 
was below $50 \%$ against cefuroxime and erythromycin. Constant screening and surveillance of MRSA infections are essential to generate important data to inform stakeholders and clinicians in effective management of MRSA infections.

\section{Authors' Contributions}

ABK: Conception and design, laboratory work, data analysis and manuscript write up. EF: Conception, design, and review of manuscript. AOO: Data analysis and critical review of manuscript. All authors read and approved the final manuscript.

\section{Acknowledgments}

This study was supported with grants from KNUST and KATH. Department of Pathology, University of Utah Medical School USA, supplied control strains and E-test strips.

\section{Competing Interests} interests.

The authors declare that they have no competing

\section{References}

1. The Center for Disease Dynamics Economics and Policy (CDDEP) Website. Methicillin-Resistant Staphylococcus aureus. Available from: http://www.cddep.org/resistancemap/mrsa. Accessed on 20-01-2016.

2. Barber M. Methicillin-resistant Staphylococci. J Clin Pathol 1961;14:385-93.

3. Scragg JN, Appelbaum PC, Govender DA. The spectrum of infection and sensitivity of organisms isolated from African and Indian children in a Durban hospital. Trans R Soc Trop Med Hyg 1978;72:325-8.

4. Park C, Pearce J. A major outbreak of methicillin resistant Staphylococcus aureus among patients and staff at Johannesburg hospital during 1986-1987. Nurs RSA 1989;4:37-9.

5. Mason PR, Kitai I, Chigonde S. Community acquired Staphylococcal skin infections in rural areas of Zimbabwe. Cent Afr J Med 1991;37:56-60.

6. Boyce JM. Update on resistant Staphylococcus aureus infections. Clin Update Infect Dis 2003;6:1-4.

7. Cosgrove SE, Sakoulas G, Perencevich EN, Schwaber MJ, Karchmer AW, Carmeli Y. Comparison of mortality associated with methicillin-resistant and methicillin-susceptible Staphylococcus aureus bacteremia: A meta-analysis. Clin Infect Dis 2003;36:53-9.

8. David MZ, Boyle-Vavra S, Zychowski DL, Daum RS. Methicillin-susceptible Staphylococcus aureus as a predominantly healthcare-associated pathogen: A possible reversal of roles? PloS One 2011;6:e18217.

9. Falagas ME, Karageorgopoulos DE, Leptidis J, Korbila IP. MRSA in Africa: Filling the global map of antimicrobial resistance. PLoS One 2013;8:e68024.

10. Odonkor ST, Newman MJ, Addo KK. Prevalence and antibiotic susceptibility profile of methicillin resistant Staphylococcus aureus in Accra, Ghana. Microb Res 2012;3:84-7.

11. Egyir B, Guardabassi L, Nielsen SS, Larsen J, Addo KK, Newman MJ, et al. Prevalence of nasal carriage and diversity of Staphylococcus aureus among inpatients and hospital staff at Korle-Bu Teaching hospital, Ghana. J Glob Antimicrob Resist 2013;1:189-93.

12. Odai SA. Prevalence of Methicillin Resistant Staphylococcus aureus (MRSA) at the Brong Ahafo Regional Hospital (Barh), Sunyani. M.Sc. Thesis, Kwame Nkrumah University of Science and Technology; 2016.

13. Clinical and Laboratory Standards Institute. Methods for Dilution Antimicrobial Susceptibility Tests for Bacteria that Grow Aerobically. $7^{\text {th }}$ ed., Vol. 23. Wayne, Pennsylvania: Clinical and Laboratory Standards Institute; 2006.

14. Bustamante ND. MRSA: A Global Threat, MD Thesis, UT Southwestern Medical School; 2011. Available from: http://www.utsouthwestern.edu/edumedia/edufiles/about us/admin offices/global health/mrsa-bustamante.pdf. Accessed on 28-10-2016.

15. Odonkor ST, Addo KK. Evaluation of three methods for detection of methicillin resistant Staphylococcus aureus (MRSA). Int J Biol Med Res 2010;2:1031-4.

16. Voss A, Milatovic D, Wallrauch-Schwarz C, Rosdahl VT, Braveny I. Methicillin-resistant Staphylococcus aureus in Europe. Eur J Clin Microbiol Infect Dis 1994;13:50-5.

17. Austin TW, Austin MA, McAlear DE, Coleman BT, Osoba AO, Thaqafi AO, et al. MRSA prevalence in a teaching hospital in Western Saudi Arabia. Saudi Med J 2003;24:1313-6.

18. Kesah C, Ben Redjeb S, Odugbemi TO, Boye CS, Dosso M, Ndinya Achola JO, et al. Prevalence of methicillin-resistant Staphylococcus aureus in eight African hospitals and Malta. Clin Microbiol Infect 2003;9:153-6.

19. Alli OA, Ogbolu DO, Bamigboye KP, Animasaun AA, Oluremi A. Distribution of genes encoding aminoglycoside modifying enzymes amongst methicillin resistant and methicillin susceptible Staphylococcus aureus isolates from Nigerian hospitals. Afr J Microbiol Res 2015;9:318-25.

20. Zetola N, Francis JS, Nuermberger EL, Bishai WR. Community-acquired meticillin-resistant Staphylococcus aureus: An emerging threat. Lancet Infect Dis 2005;5:275-86.

21. Andersen BM, Lindemann R, Bergh K, Nesheim BI, Syversen G, Solheim N, et al. Spread of methicillin-resistant Staphylococcus aureus in a neonatal intensive unit associated with understaffing, overcrowding and mixing of patients. J Hosp Infect 2002;50:18-24.

22. Adcock PM, Pastor P, Medley F, Patterson JE, Murphy TV. Methicillin-resistant Staphylococcus aureus in two child care centers. J Infect Dis 1998;178:577-80.

23. Sackey J. Korle-Bu Battles Outbreak of Deadly BacteriaLocal News. Available from: http://www.edition.myjoyonline.com/pages/news/201201/80725.php. Retrieved on 08-12-2012.

24. Kumari DN, Keer V, Hawkey PM. Comparison and application of ribosome spacer DNA amplicon polyrnorphisms and pulsed-field gel electrophoresis for differentiation of methicillin-resistant Staphylococcus aureus strains. Clin Microbiol 1997;35:881.

25. Udo EE, Pearman JW, Grubb WB. Genetic analysis of community isolates of methicillin-resistant Staphylococcus aureus in Western Australia. J Hosp Infect 1993;25:97-108.

26. Anupurba S, Sen MR, Nath G, Sharma BM, Gulati AK, Mohapatra TM. Prevalence of methicillin resistant Staphylococcus aureus in a tertiary referral hospital in eastern Uttar Pradesh. Indian J Med Microbiol 2003;21:49-51.

27. Fitzroy AO, Michael L. Methicillin-resistant Staphylococcus aureus prevalence: Current susceptibility patterns in Trinidad. BMC Infect Dis 2006;6:83.

28. Turnidge JD, Bell JM. Methicillin-resistant Staphylococcal aureus evolution in Australia over 35 years. Microb Drug Resist 2000;6:223-9.

29. Gosbell IB, Mercer JL, Neville SA, Crone SA, Chant KG, Jalaludin BB, et al. Non-multiresistant and multiresistant methicillin-resistant Staphylococcus aureus in community-acquired infections. Med J Aust 2001;174:627-30. 